УДК 332.74

DOI: $10.33764 / 2687-041 X-2021-1-189-194$

\title{
ВЛИЯНИЕ РЫНОЧНОЙ СТОИМОСТИ ОБЪЕКТОВ НЕДВИЖИМОСТИ НА КАДАСТРОВУЮ ОЦЕНКУ
}

\section{Сталина Сергеевна Врублевская}

Сибирский государственный университет геосистем и технологий, 630108, Россия, г. Новосибирск, ул. Плахотного, 10, обучающийся, e-mail: smile_983@mail.ru

\section{Анастасия Леонидовна Ильиных}

Сибирский государственный университет геосистем и технологий, 630108, Россия, г. Новосибирск, ул. Плахотного, 10, кандидат технических наук, доцент кафедры кадастра и территориального планирования, тел. (383) 361-01-09, e-mail: linykh_al@mail.ru

В статье рассмотрены две важные категории: рыночная стоимость и кадастровая стоимость, обозначены их признаки, общие черты и основные различия. Уточнен принцип экономической обоснованности применительно к определению кадастровой стоимости, проведена попытка установить взаимосвязь между данными стоимостями на основных этапах государственной кадастровой оценки. Выведены ключевые проблемы, которые приводят к росту количества случаев оспаривания результатов определения кадастровой стоимости и сдерживают развитие рыночной составляющей системы кадастровой оценки в России.

Ключевые слова: кадастровая оценка, рыночная стоимость, недвижимость, объект, рынок недвижимости

\section{IMPACT OF THE MARKET VALUE OF REAL ESTATE PROPERTIES ON CADASTRE ASSESSMENT}

\section{Stalina S. Vrublevskaya}

Siberian State University of Geosystems and Technologies, 10, Plakhotnogo St., Novosibirsk, 630108, Russia, Student, e-mail: smile_983@mail.ru

\section{Anastasia L. Ilyinykh}

Siberian State University of Geosystems and Technologies, 10, Plakhotnogo St., Novosibirsk, 630108, Russia, Ph. D., Assoc. Prof., Department of Cadastre and Territorial Planning, phone: (383)344-31-73, e-mail: ilinykh_al@mail.ru

The article discusses two important categories: market value and cadastral value; their signs, common features and main differences are indicated. The principle of economic feasibility was clarified in relation to the determination of the cadastral value, an attempt to establish the relationship between these values at the main stages of the state cadastral valuation was made. The main problems that lead to an increase in the number of cases of challenging the results of determining the cadastral value and hinder the development of the market system of cadastral valuation in Russia are identified.

Keywords: cadastral assessment, real estate, object, market

Выход рынка недвижимости в «свободное плавание» в большей степени опирается на спрос в данной сфере, без учета постоянных стоимостных значений продукта. Специфика рынка недвижимости ориентировалась на «стихий- 
ные» показатели: поддержание в надлежащем состоянии объектов, являющиеся второстепенными стоимостными признаками.

Различия в расчетной величине рыночной и кадастровой стоимости недвижимости вызывает дискуссионный резонанс. Разные исследователи изучали причины разброса этих стоимостей. Несоответствие объяснялось как несовершенством методологии массовой оценки, так и временными характеристиками проведения оценки [1-5].

В научно-исследовательской литературе предлагались конкретные методы для устранения этих несоответствий, а именно [6, 7]:

- проведение мониторинга рынка недвижимости;

- создание актуальной базы данных по рынку недвижимости.

Для получения максимально приближенных результатов определения кадастровой стоимости к рыночной необходим учет существенных или разноуровневых факторов стоимости объектов оценки, что в большей степени ориентировано на субъективный подход.

На протяжении длительного времени государство для целей налогообложения использовало термин «инвентаризационная стоимость», который включал ограниченный набор параметров, отражающих исключительно физические особенности строительства и эксплуатации объектов недвижимости. С 2013 г. в соответствии с Федеральным законом от 24 июля 2007 г. № 221-Ф3 «О кадастровой деятельности» государственный технический учет и расчет инвентаризационной стоимости объектов недвижимости перестали осуществляться [8]. Термин «кадастровая стоимость» внес большую конкретизацию и не только в отношении налогообложения недвижимости.

Принятый Закон [8] регулирует отношения, возникающие в связи с осуществлением кадастровой деятельности, деятельности саморегулируемых организаций кадастровых инженеров, национального объединения саморегулируемых организаций кадастровых инженеров (далее - кадастровые отношения), тем самым упорядочил и ограничил деятельность организаций, способных дать сведения о характеристиках недвижимости для их кадастровой оценки.

Была установлена правовая основа кадастровых отношений, в основу которой положен нововведенный Закон и другие федеральные законы и издаваемые в соответствии с ними иные нормативные правовые акты Российской Федерации.

Кадастровая стоимость - это рыночная стоимость объекта недвижимости, которая устанавливается путем проведения государственной кадастровой оценки.

Если рыночную стоимость определяет спрос и предложение, то кадастровая стоимость для конкретного объекта недвижимости определяется в массовом порядке в соответствии с требованиями законодательства об оценочной деятельности. 
Сведения о кадастровой стоимости объекта недвижимости заносятся в Единый государственный реестр недвижимости (ЕГРН).

Порядок проведения государственной кадастровой оценки регулируется Федеральным законом «О государственно кадастровой оценке» от 3 июля 2016 г. № 237-Ф3. Кадастровая стоимость определяется в ходе государственной кадастровой оценки. Решение о проведении государственной кадастровой оценки принимают региональные органы власти или органы местного самоуправления [9].

В Федеральном законе от 29 июля 1998 г. № 135-Ф3 «Об оценочной деятельности в Российской Федерации» [10] прописано, что под рыночной стоимостью объекта оценки понимается наиболее вероятная цена, по которой данный объект оценки может быть отчужден на открытом рынке в условиях конкуренции, когда стороны сделки действуют разумно, располагая всей необходимой информацией, а на величине цены сделки не отражаются какие-либо чрезвычайные обстоятельства. При этом толкование термина «кадастровая стоимость» выглядит несколько иначе, так под ней понимается стоимость, установленная в следующих случаях:

- при проведении государственной кадастровой оценки;

- рассмотрении споров о результатах определения кадастровой стоимости;

- учете новых объектов или внесении количественных и качественных изменений в характеристики объекта.

Таким образом, в Федеральном законе № 135-Ф3 дается четкое понимание обстоятельств, при которых формируется рыночная стоимость, в то время как для кадастровой стоимости перечисляются ситуации, в которых она должна использоваться, без характеристики особенностей ее формирования. Раскрытие термина осуществлено в Федеральном законе от 3 июля 2016 г. №.237-Ф3 «О государственной кадастровой оценке».

Так, в ст. 3 указано, что кадастровая стоимость - это стоимость объекта недвижимости, определенная в установленном порядке, предусмотренном законодательством, и в результате проведения государственной кадастровой оценки в соответствии с методическими указаниями о государственной кадастровой оценке [9].

Более точное толкование законодатель дает в Методических указаниях о государственной кадастровой оценке, утвержденных Приказом Минэкономразвития России от 12 мая 2017 г. № 226, где в п. 1.2 прописано, что определение кадастровой стоимости предполагает расчет наиболее вероятной цены объекта недвижимости, по которой он может быть приобретен, исходя из возможности продолжения фактического вида его использования независимо от ограничений на распоряжение этим объектом недвижимости [1].

Рассмотрим в таблице основные признаки и различия рыночной и кадастровой стоимости. 
Основные признаки рыночной и кадастровой стоимости

\begin{tabular}{|c|c|c|}
\hline \multirow{2}{*}{ Признаки } & \multicolumn{2}{|c|}{ Проявление в стоимости } \\
\hline & рыночная & кадастровая \\
\hline Цель проведения & $\begin{array}{c}\text { Баланс интересов про- } \\
\text { давца и покупателя при со- } \\
\text { вершении сделки }\end{array}$ & $\begin{array}{l}\text { Стоимость для целей } \\
\text { налогооблажения }\end{array}$ \\
\hline $\begin{array}{l}\text { По отношению к соб- } \\
\text { ственнику }\end{array}$ & $\begin{array}{c}\text { Наиболее вероятная } \\
\text { цена, по которой объект мо- } \\
\text { жет быть отчужден }\end{array}$ & $\begin{array}{c}\text { Наиболее вероятная } \\
\text { цена, по которой объект мо- } \\
\text { жет быть приобретен }\end{array}$ \\
\hline База расчета & $\begin{array}{l}\text { Набор объектов- } \\
\text { аналогов }\end{array}$ & $\begin{array}{r}\text { Рыночная информация } \\
\text { в целом по сегменту объекта } \\
\text { оценки }\end{array}$ \\
\hline Обременения & Учитываются & $\begin{array}{r}\text { Не учитываются (за } \\
\text { искл. П.10 ФСО №4) [11] }\end{array}$ \\
\hline Вид использования & $\begin{array}{c}\text { Наиболее эффектив- } \\
\text { ный }\end{array}$ & Текущий фактический \\
\hline Вид оценки & субъективная & Массовая \\
\hline $\begin{array}{l}\text { Ценообразующие фак- } \\
\text { торы }\end{array}$ & Все необходимые & Ограниченный набор \\
\hline Периодичность & При необходимости & Систематическая \\
\hline $\begin{array}{l}\text { Подвижность во вре- } \\
\text { мени }\end{array}$ & Динамичная & Статичная \\
\hline $\begin{array}{l}\text { Актуальность резуль- } \\
\text { татов оценки }\end{array}$ & До 6 месяцев & От 3 до 5 лет \\
\hline
\end{tabular}

Анализируя данные в таблице, можно сделать вывод, что рыночная и кадастровая стоимости недвижимости имеют общую тесную экономическую природу, но следует учитывать, что кадастровая стоимость, базируясь на рыночной информации, является вполне самостоятельным видом стоимости [12, 13].

С учетом вышеизложенного можно сделать вывод, что в России в настоящее время формируется рыночная система кадастровой стоимости. Однако для устойчивого формирования данной системы существует ряд объективных трудностей:

- встречается низкое качество и недостаточное количество информации в отношении земельных участков, содержащихся в Едином государственном реестре недвижимости (ЕГРН). Некорректные исходные данные ограничивают возможности экономического обоснования кадастровой стоимости, в результате итоги оценки либо превышают рыночные показатели, либо занижены [14];

- неоднозначность вида разрешенного использования земельного участка. Практика показывает, что в некоторых случаях вид разрешенного использования участка не дает возможности однозначно отнести его ни к одной из функциональных групп типового перечня видов разрешенного использования. Единый порядок определения видов использования отсутствует [15]; 
- отсутствие в ЕГРН информации по существенным характеристикам объектов капитального строительства, которые значительно влияют на кадастровую стоимость. Зачастую база ЕГРН не содержит той информации об объекте недвижимости, которая составляет рыночную стоимость объекта и является фактически ценообразующей. Например, количество комнат в квартире, площадь кухни, тип санузла и т.п [16];

- отсутствие достоверной рыночной информации. ЕГРН может содержать информацию по сделкам с недвижимостью, не отображающую фактические ценовые данные, которые могут быть либо завышены, либо занижены (по негласной договоренности между продавцом и покупателем) [17];

- неразвитость рынка недвижимости в некоторых сегментах, районах в регионах России [18];

- трудности в подборе адекватной оценочной модели. Применение математических методов в процессе кадастровой оценки объектов оказывают влияние на стоимость недвижимости в сторону ее укрупнения $[19,20]$.

Таким образом, рыночная стоимость объекта по косвенным признакам влияет на определение кадастровой стоимости. Основной задачей деятельности государства остается создание единой нормативно-правовой базы для проведения оценок и расчета кадастровой стоимости с учетом отдельных и определяющих факторов рыночной стоимости, но дающих объективную оценку стоимости. Вместе с тем, искажение результатов кадастровой оценки в сторону занижения приводит к прямым финансовым потерям местных бюджетов, и, наоборот, завышение влечет за собой рост социальной напряженности и учащение обращений по оспариванию кадастровой стоимости.

\section{БИБЛИОГРАФИЧЕСКИЙ СПИСОК}

1. Методические указания о государственной кадастровой оценке [Электронный ресурс]: приказ Минэкономразвития России от 12.05.2017. № 226. - Доступ из справ.-правовой системы «КонсультантПлюс». - Загл. с экрана.

2. Учинина Т. В. Рыночная и кадастровая стоимость земельных участков: причины несоответствия. // Вестн. ПГУАС: строительство, наука и образование. - 2017. - № 1. C. $106-110$.

3. Курманчук К.С. Анализ кадастровой и рыночной оценки объекта недвижимости / К.С. Курманчук // Вестник современных исследований. - 2019. - № 2.20 (29). - С. 39-49.14. Грибовский С. Массовая оценка недвижимости // Финансовый бизнес. 2000. - №4. - с. 43-45.

4. Штань М. В. Конфликт между рыночной и кадастровой стоимостями / М. В. Штань // Имуществ. отношения в РФ. - 2018. - № 8 (203). - С. 34-49.

5. Тиндова М. Г. Анализ различий между рыночной и кадастровой стоимостью объектов недвижимости / М. Г. Тиндова, О. П. Корякина, И. Д. Рамазанова // Наука и общество. 2012. - № 5. - C. 46-50.

6. Алексеев А. О. К вопросу об интеллектуальном анализе, массовой оценке и управлении рынком недвижимости регионов России / А. О. Алексеев, В. А. Харитонов, В. Л. Ясницкий // Приклад. математика и вопросы упр. - 2017. - № 1. - С. 87-99.

7. Бердникова В.Н. Взаимосвязь кадастровой и рыночной стоимости. / Вестник Челябинского государственного университета. 2019. № 9 (431). Экономические науки. Вып. 66. C. $210-216$. 
8. Федеральный закон от 24 июля 2007 г. № 221-Ф3 «О кадастровой деятельности» / электронный ресурс http://www.consultant.ru/document/cons_doc_LAW_70088/.

9. О государственной кадастровой оценке [Электронный ресурс] : федер. закон от 03.07.2016 № 237-Ф3. - Доступ из справ.-правовой системы «КонсультантПлюс». - Загл. с экрана.

10. Об оценочной деятельности в Российской Федерации [Электронный ресурс] федер. закон от от 29.07.98 г. № 135-Ф3 - Доступ из справ.-правовой системы «КонсультантПлюс». Загл. с экрана.

11. Приказ Минэкономразвития России от 22.10.2010 N 508 (ред. от 22.06.2015) "Об утверждении Федерального стандарта оценки "Определение кадастровой стоимости (ФСО N 4)".

12. Анализ ценообразующих факторов, оказывающих влияние на кадастровую стоимость недвижимости / А. В. Дубровский, А. Л. Ильиных, О. И. Малыгина, В. Н. Москвин, А. В. Вишнякова // Вестник СГУГИТ. - 2019. - № 2 (24). - С. 150-169.

13. Государственный земельный кадастр / В.Л. Баденко, В.В. Гарманов, Г.К Осипов // учеб. пособие. - СПб. : Университет СПбГПУ. - 2002 - 231 с.

14. Экономический анализ и оценка недвижимости / Озеров Е.С. // Санкт-Петербург: МКС, 2007. - $535 \mathrm{c}$.

15. Основы землепользования и землеустройства / А. С. Чешев, В. Ф. Вальков // 2. изд., доп. и перераб. - М. : МарТ, 2002. - 543 с.

16. Кадастровая оценка земли / А. П. Воронцов // Учебное пособие. М.: - ИКФ «ЭКМОС», 2002. - $210 \mathrm{c}$.

17. Оценка недвижимости / А. Г. Грязнова, М. А. Федотова // Учебник - 2-е изд., перераб. и доп. М. 2002. -560 с.

18. Оценка земли и иной недвижимости / Г. В.Ломакин // Учебно-практическое пособие. М.: ГУЗ, 2001. -211 с.

19. Земельный кадастр / А.С. Чешев, И.П. Фесенко // Учеб. для студентов вузов, обучающихся по специальностям "Землеустройство", "Зем. кадастр", "Гор. кадастр" // М. : Приор : Эксперт. бюро, 2001. - 362 с.

20. Варламов А.А. Земельный кадастр: в 6 т. Т.5. Оценка земли и иной недвижимости / А.А. Варламов, А.В. Севостьянов. - М.: КолосС, 2004. - 528 с. - (Международная ассоциация «Агрооборазование»).

(C) С. С. Врублевская, А. Л. Ильиньх, 2021 